18

\title{
Фотоуправляемые обратимые изменения электронных и колебательных спектров фотохромного диарилэтена в различных наноструктурированных системах
}

\author{
(С) Г.Т. Василюк ${ }^{1}$, П.В. Карпач ${ }^{1}$, С.Д. Гоголева ${ }^{1}$, А.О. Айт ${ }^{2}$, В.А. Барачевский ${ }^{2}$, С.А. Маскевич ${ }^{3}$ \\ ${ }^{1}$ Гродненский государственный университет им. Янки Купалы, \\ 230023 Гродно, Беларусь \\ ${ }^{2}$ Центр фоотохимии ФНИЦ „Кристаллография и фотоника“ РАН, \\ 119421 Москва, Россия \\ ${ }^{3}$ Белорусский государственный университет, МГЭИ им. А.Д. Сахарова Бгу, \\ 220070 Минск, Беларусь \\ e-mail: vasilyuk@grsu.by
}

Поступила в редакцию 10.12.2021 г.

В окончательной редакции 20.12.2021 г.

Принята к публикации 22.12.2021 г.

\begin{abstract}
Представлен анализ результатов комплексных экспериментальных и теоретических исследований фотоиндуцированных изменений спектральных свойств фотохромного диарилэтена в различных наноструктурированных системах. Свойства диарилэтена исследованы в растворах в присутствии коллоидных металлических и полупроводниковых наночастиц, а также в виде твердофазных композитных наноструктурированных систем „ядро-оболочка“ на основе коллоидных наночастиц с оболочкой из молекул диарилэтена (в том числе в полимерной матрице). Обнаружено фотоиндуцированное обратимое изменение электронных и колебательных спектров диарилэтена в различных исследованных матрицах. Результаты могут быть использованы при создании оптико-электронных фотопереключаемых элементов для устройств памяти сверхбольшой емкости, фотоуправляемых молекулярных переключателей и сенсоров.
\end{abstract}

Ключевые слова: фотохромизм, диарилэтены, нанокомпозиты, квантовые точки, электронные спектры, колебательные спектры, флуоресценция, индуктивно-резонансный перенос энергии, квантово-химические расчеты.

DOI: $10.21883 / \mathrm{OS} .2022 .03 .52175 .3023-21$

\section{Введение}

В современной электронике одним из направлений развития является разработка гибридных устройств, свойства которых зависят от молекулярной структуры применяемых соединений, с потенциальной возможностью использования в оптических интегральных схемах $[1,2]$. Для этих целей наиболее перспективны фотохромные соединения, особенно термически необратимые диарилэтены (ДАЭ) [3-5], обратимо изменяющие свои свойства под действием света и используемые при создании фотопереключателей различного типа [6].

Особый интерес представляют наноструктурированные фотохромные гибридные (композитные) системы [7], включающие молекулы фотохромных органических соединений, в частности из класса ДАЭ, и наночастицы благородных металлов, а именно золота [8-14] и серебра $[9,15,16]$, а также неорганических полупроводников [17].

Ранее была теоретически предсказана $[18,19]$ и экспериментально изучалась $[20,21]$ возможность повышения эффективности фотохимических процессов наряду с усилением сигнала комбинационного рассеяния (КР) света и люминесценции при адсорбции молекул на поверхности металла с наноразмерными шероховатостями, связанная с плазмонными эффектами (рис. 1,a). Проводилось и экспериментальное изучение свойств фотохромных соединений вблизи наноструктурированной поверхности благородных металлов [22].

Плазмонное усиление электромагнитного поля вблизи наночастицы металла обеспечивает повышение эффективности фотохромных превращений благодаря как формированию двухфотонной фотохромной реакции циклореверсии ДАЭ, так и повышению скорости однофотонной реакции в 2-5 раз [23]. Изомеризация переключателя (фотохромной молекулы) влечет за собой изменение его электронных свойств, тем самым изменяя диэлектрическую проницаемость в непосредственной близости от поверхности наночастицы, что позволяет обратимым образом управлять частотой плазмонного резонанса и межчастичным взаимодействием [23].

В перспективных молекулярных системах, содержащих флуорофор (например, полупроводниковую квантовую точку (KT) $\mathrm{CdSe} / \mathrm{ZnS}$ ) и фотохромный фрагмент, фототрансформация фотохромной молекулы может приводить к модуляции интенсивности флуоресценции вследствие изменения квантового выхода флуорофора (при индуктивно-резонансном переносе энергии (FRET) с 
флуорофора на фотохром), а также в результате перепоглощения света флуоресценции фотохромным соединением (эффект внутреннего фильтра) [23-25].

На основе композитных структур „наночастица-молекулярный переключатель“ возможно создание наносистем, работающих в неравновесном режиме, которые могут изменять внутренний порядок (структуру) и адаптироваться к внешним воздействиям.

В настоящей работе (в развитие предыдущих исследований авторов [26-34]) представлен анализ результатов комплексного экспериментального и теоретического изучения фотоиндуцированных изменений спектральных свойств фотохромного ДАЭ1 в различном окружении. Судя по результатам предыдущих исследований ДАЭ1 обладает хорошими фотохромными свойствами (светочувствительностью и амплутудой динамического изменения спектрального фотопоглощения) как в раствоpax, так и в твердофазных пленках. Большой интерес представляет исследование свойств этого соединения в нанокомпозитных структурах (системах) с металлическими наночастицами - для возможного применения в фотоуправляемых переключателях электрического и оптического сигнала [4,23] или сенсорах [23], а также с полупроводниковыми наночастицами - для применения в флуоресцентных фотопереключаемых хемосенсорах и мультифункциональных фотоэлектроуправляемых дисплеях [23].

\section{Экспериментальная часть}

Объектами исследования в настоящей работе служили фотохромное соединение ДАЭ1 из класса циклопентеновых производных ДАЭ, а также композитные системы на основе молекул этого соединения, содержащих наночастицы серебра, золота или $\mathrm{CdSe} / \mathrm{ZnS}$ (в том числе пленки и полимерные наносферы, включающие в себя полупроводниковые КТ $\mathrm{CdSe} / \mathrm{ZnS}$ и молекулы ДАЭ1, схема 1).

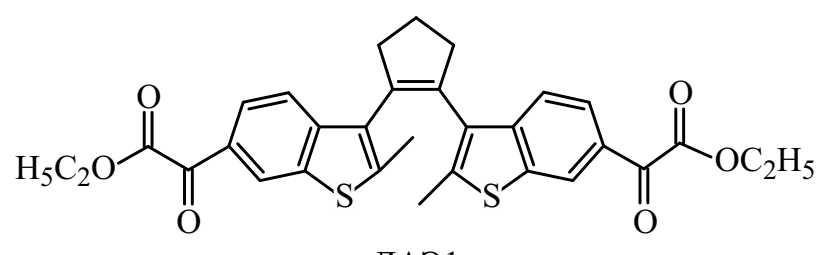

ДАЭ1

С использованием методов спектрофотометрии, колебательной спектроскопии (инфракрасного (ИК) поглощения, комбинационного рассеяния (КР) и гигантского комбинационного рассеяния (ГКР) света и квантовой химии исследованы спектральные характеристики и структура полученных фотохромных нанокомпозитов в растворах и твердофазных пленках и их изменения при фотохромных превращениях. Методами стационарной и кинетической флуориметрии исследовалась фотоиндуцированная модуляция флуоресценции таких систем, в том числе вследствие FRET.
Наночастицы серебра с размерами 30-40 nm были получены цитратным восстановлением ионов серебра в водном растворе [35], а с размерами 8-10 nm боргидридным восстановлением серебра в водном растворе [36]. Наночастицы золота с диаметром около $20 \mathrm{~nm}$ были приготовлены цитратным восстановлением золота в водном растворе [37,38]. Для приготовления коллоидных пленок серебра и золота использовался метод послойного осаждения коллоидов серебра (или нанокомпозитных систем из частиц благородных металлов с оболочкой из молекул фотохромных ДАЭ) путем окунания стеклянной подложки в коллоидный раствор и последующего высушивания [26]. Максимум плазмонной полосы поглощения твердофазных систем на основе боргидридного золя серебра расположен при $415 \mathrm{~nm}$, а на основе цитратного золя - около $428 \mathrm{~nm}$. Для получения нанокомпозитных систем, содержащих наночастицы серебра или золота с оболочкой из молекул фотохромных ДАЭ (рис. 1,a), растворы наночастиц благородных металлов и фотохромных соединений смешивались в объемном соотношении $1: 1$ [26].

Используемые в работе полупроводниковые наночастицы - KT CdSe/ZnS, содержащие ядро CdSe и пассивирующую оболочку из более широкозонного материала $\mathrm{ZnS}$, синтезированы в НИИ ФХП БГУ согласно адаптированному протоколу.

Фотохромные системы на основе ДАЭ и КТ CdSe/ZnS готовили в хлороформе или в толуоле, используя методики [30]. Кроме того, использовались синтезированные по методике профессора М.В. Артемьева [31] полимерные наносферы, включающие в себя полупроводниковые КТ и молекулы фотохромного соединения ДАЭ1 (рис. 1, $b$ ). Для получения таких полимерных наносфер был применен метод введения молекул ДАЭ1 в тонкую полимерную оболочку поверх гидрофобных КТ $\mathrm{CdSe} / \mathrm{ZnS}$ во время их инкапсуляции и солюбилизации в воде с помощью известной процедуры [39].

Спектрально-кинетические исследования фотохромных превращений ДАЭ в растворах и в композитных наноструктурах проводились с использованием спектрофотометров SPECORD 200 (Carl Zeiss, Германия) и Cary 50 Bio (Varian, Австралия), а также лампы LC-4 (Hamamatsu, Япония). Для выделения УФ составляющей излучения использовался светофильтр УФС-1. Облучение образцов видимым светом осуществлялось через светофильтр ЖС-16. В некоторых случаях для облучения использовались светодиоды с максимумами полос излучения при 365 (LED365) и 514 nm (LED514). Полуширины полос излучения светодиодов LED365 и LED514 составляли 9 и $32 \mathrm{~nm}$, а оптическая мощность - 0.45 и $3 \mathrm{~W}$ соответственно. Время облучения, необходимое для перевода ДАЭ между формами А и $\mathrm{B}$, определялось на основании спектров поглощения, измеренных в состоянии равновесия. При регистрации спектров поглощения не учитывалось возможное рассеяние и отражение от образца. 
$a$
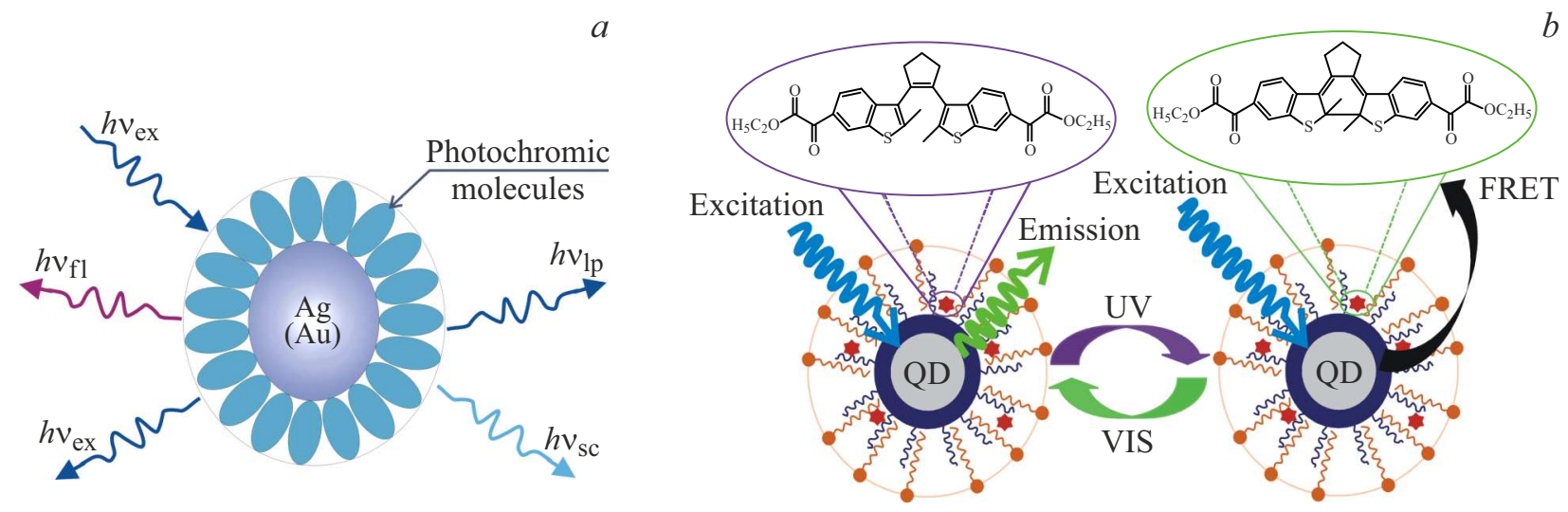

Рис. 1. (a) Схемы оптических процессов в твердофазных фотохромных нанокомпозитных системах на основе металлических наночастиц и $(b)$ фотоиндуцированной модуляции флуоресценции нанокомпозитных полимерных наносфер, содержащих полупроводниковую наночастицу (КТ) и молекулы ДАЭ1 в процессе фотохромных превращений ДАЭ.

Регистрация ИК спектров осуществлялась с применением ИК фурье-спектрометра Nicolet iS10 (Thermo Scientific, США). Для регистрации спектров КР и ГКР света применялся 3D сканирующий конфокальный рамановский микроскоп со спектрометром Nanofinder $\mathrm{S}$ (Solar TII, Беларусь). Спектры КР и ГКР исследуемых объектов регистрировались в диапазоне $200-1800 \mathrm{~cm}^{-1}$. Плотность мощности лазерного излучения на образце составляла $5-10 \mathrm{~mW} / \mathrm{mm}^{2}$.

Для регистрации спектров флуоресценции использовался спектрофлуориметр СМ2203 (Солар, Беларусь), а для измерения длительности затухания флуоресценции - лабораторная установка, описанная в [40], работающая в режиме время-коррелированного счета фотонов (TCSPC) [41]. Источником возбуждения служил пикосекундный диодный лазер PDL 800B с лазерными головками LDH-405 и LDH-470 (PicoQuant, Германия), генерирующий импульсы света длительностью $70 \mathrm{ps} \mathrm{c}$ частотой следования до $40 \mathrm{MHz}$ и длинами волн 407 и $467 \mathrm{~nm}$ соответственно. В систему регистрации входят фотоприемный блок РМА-182 и система для времякоррелированного счета фотонов TimeHarp200 фирмы PicoQuant (Германия).

При интерпретации колебательных и электронных спектров использовались результаты квантовохимических расчетов. В настоящей работе все квантовохимические расчеты выполнены с использованием программного пакета PC GAMESS 7.1.G (Firefly). Равновесная геометрия и колебательные спектры молекулы ДАЭ1 рассчитаны с использованием метода RHF. Расчеты колебательных (ИК и КР) спектров молекул проводились с использованием базиса 6-31G. Расчет поверхности потенциальной энергии (ППЭ, сечение поверхности) в зависимости от расстояния между атомами углерода, участвующими в реакции фотоизомеризации, выполнен с помощью методов теории функционала плотности (DFT), гибридного трехпараметрического обменного функционала Беке с корреляционным функционалом Ли-Янга-Парра (В3LYP) [42-44]. Для вычисления энергии основного $\left(S_{0}\right)$ и возбужденных $\left(S_{1}\right.$, $\left.S_{2}, S_{3}\right)$ состояний были использованы методы DFT и TDDFT соответственно (с использованием функционала B3LYР и базиса 6-31G). Сечение ППЭ молекулы ДАЭ1 получали при использовании в качестве координаты реакции расстояния между атомами углерода, между которыми образуется (разрывается) связь в ходе реакции обратимой фотоизомеризации. Сечение ППЭ основного состояния получали методом DFT путем фиксации упомянутого расстояния (при каждом значении этого расстояния - координаты реакции) и оптимизации при этом остальной структуры молекулы. При расчете сечений ППЭ состояний $S_{1}, S_{2}, S_{3}$ использовались метод TD DFT и геометрия молекулы в каждой точке, полученная при расчете ППЭ основного состояния $S_{0}$.

\section{Результаты и их обсуждение}

\section{Расчеты электронной структуры ДАЭ1 и ее фотопревращений}

Фотохромные превращения ДАЭ обусловлены обратимой валентной фотоизомеризацией между открытой $(\mathrm{A})$ и циклической (В) формами (схема 2) [3-5]:

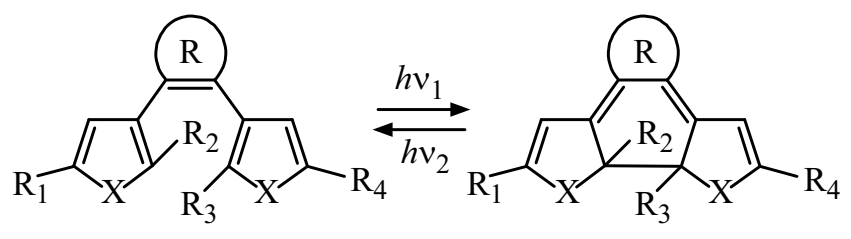

A

$\mathrm{B}$

Открытый бесцветный изомер А, поглощая УФ излучение, обратимо превращается в окрашенный изомер В, который под действием видимого излучения, поглощаемого им, снова превращается в исходный открытый изомер. Отличительной особенностью фотохромных 

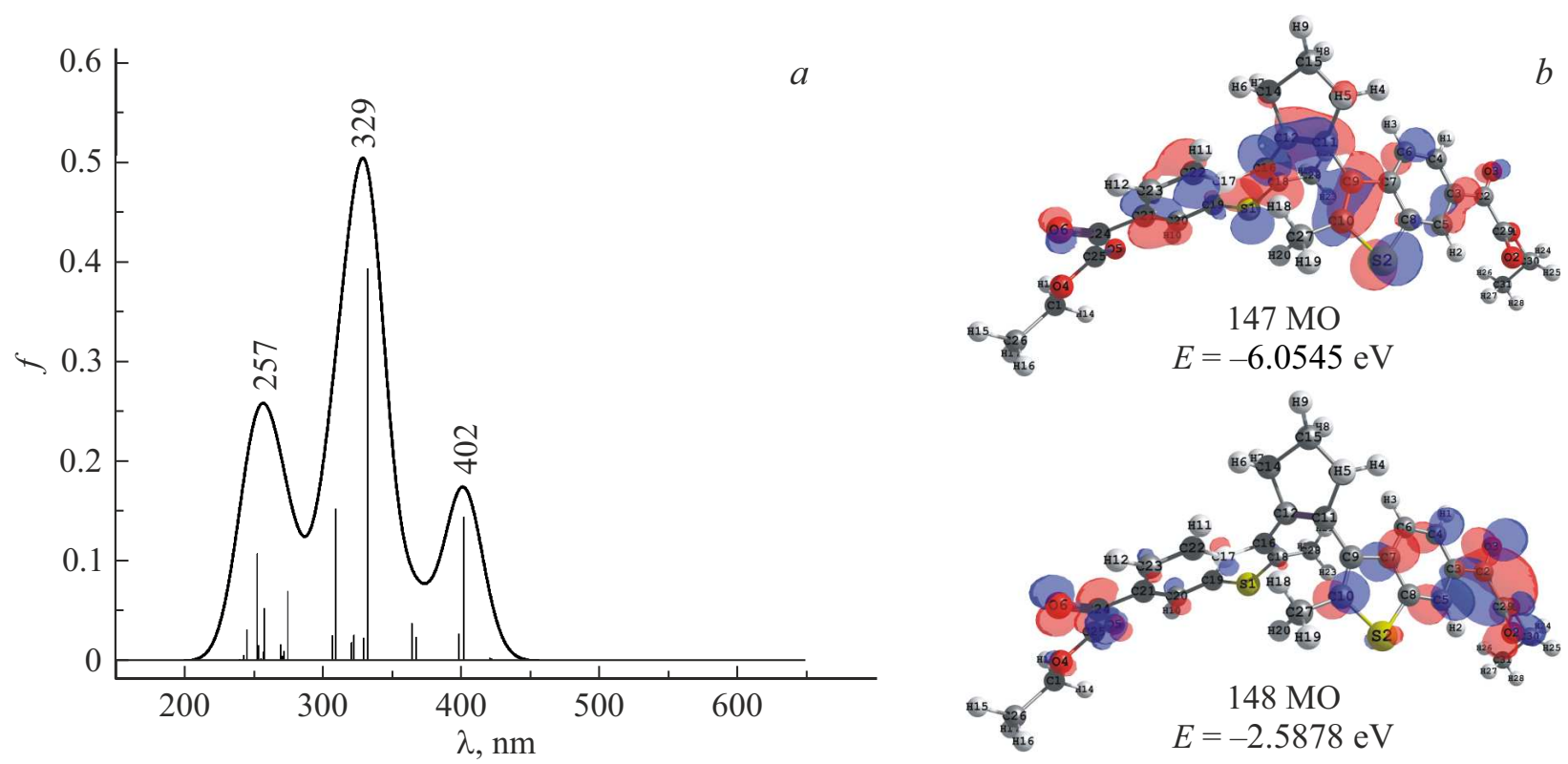

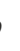
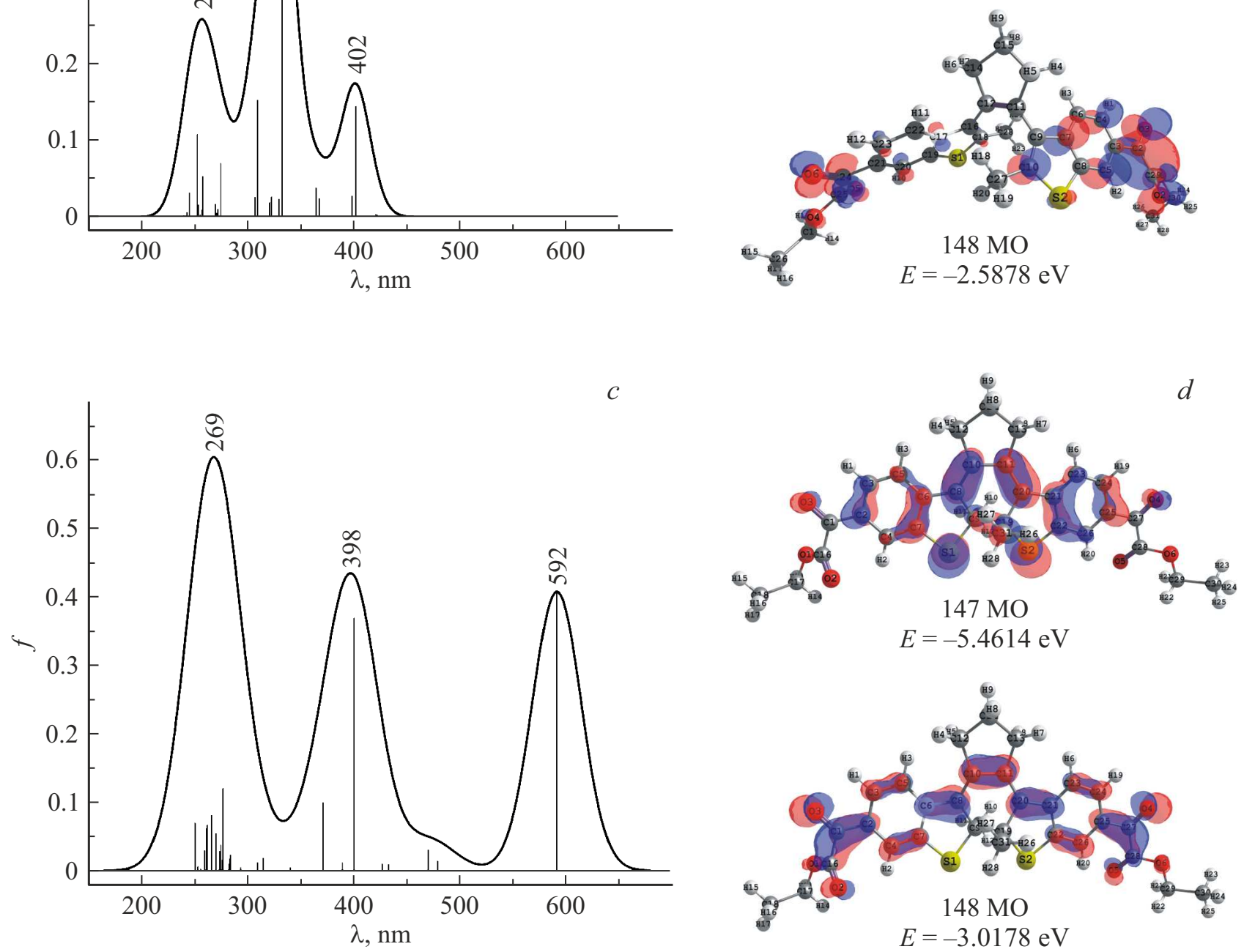

Рис. 2. Расчетные спектры электронного поглощения $(a, c)$, формы граничных МО, участвующих в формировании спектра поглощения ДАЭ1 $(b, d)$ открытого $(a, b)$ и циклического $(c, d)$ изомеров молекулы ДАЭ1.

ДАЭ является термодинамическая устойчивость обоих изомеров.

Для интерпретации результатов, полученных экспериментальными методами электронной спектроскопии, a также для анализа механизмов фотоиндуцированных превращений молекулы ДАЭ1 проведено квантовохимическое исследование электронной структуры и свойств этой молекулы. Результаты (расчетные спектры электронного поглощения и сечения ППЭ состояний $S_{0}$, $S_{1}, S_{2}, S_{3}$ молекулы ДАЭ1) приведены на рис. 2,3 и в табл. $1,2$.
Из рис. 2, $a$ и табл. 1 видно, что для открытого изомера ДАЭ1 наиболее интенсивные полосы поглощения (с максимумом при $333 \mathrm{~nm}$ и силе осциллятора 0.39; с максимумом при $402 \mathrm{~nm}$ и силе осциллятора $0.15)$ относятся к переходам в возбужденные синглетные состояния молекулы: $S_{0} \rightarrow S_{7}, S_{0} \rightarrow S_{3}$ соответственно. Возбуждение электрона с 145 молекулярной орбитали (МО) на 148 МО дает главный вклад в полосу поглощения при $333 \mathrm{~nm}$; с $147 \mathrm{MO}$ (НОМО) на 148 MO (LUMO) - в полосу поглощения при $402 \mathrm{~nm}$ (рис. $2, b)$. Результаты расчетов показывают, что при 
Таблица 1. Электронная структура открытого и циклического изомеров молекулы ДАЭ1, рассчитанная относительно основных пиков

\begin{tabular}{c|c|c|c|c|c}
\hline Изомер & Состояние & $\lambda, \mathrm{nm}$ & $\Delta E, \mathrm{eV}$ & $\begin{array}{c}\text { Разложение волновых функций } \\
\text { по однократно возбужденной конфигурации }\end{array}$ & $f$ \\
\hline \multirow{2}{*}{ Открытый } & $S_{0} \rightarrow S_{23}$ & 253 & 4.90 & $\begin{array}{l}-0.61(146 \rightarrow 151)+0.49(147 \rightarrow 152)-0.40 \\
(140 \rightarrow 149)-0.20(145 \rightarrow 150)\end{array}$ & 0.11 \\
& $S_{0} \rightarrow S_{7}$ & 333 & 3.72 & $\begin{array}{l}-0.78(145 \rightarrow 148)-0.34(144 \rightarrow 149) \\
+0.29(145 \rightarrow 149)+0.29(146 \rightarrow 149)\end{array}$ & 0.39 \\
& $S_{0} \rightarrow S_{3}$ & 402 & 3.08 & $\begin{array}{l}-0.98(147 \rightarrow 148)+0.09(143 \rightarrow 148)-0.09 \\
(145 \rightarrow 148)\end{array}$ & 0.15 \\
\hline \multirow{2}{*}{ Циклический } & $S_{0} \rightarrow S_{18}$ & 277 & 4.47 & $\begin{array}{l}-0.36(135 \rightarrow 148)+0.35(142 \rightarrow 149)-0.34 \\
(137 \rightarrow 148)-0.32(147 \rightarrow 152)\end{array}$ & 0.12 \\
\cline { 2 - 6 } & $S_{0} \rightarrow S_{6}$ & 401 & 3.09 & $\begin{array}{l}-0.85(145 \rightarrow 148)-0.36(146 \rightarrow 149)-0.25 \\
(147 \rightarrow 150)\end{array}$ & 0.37 \\
\cline { 2 - 6 } & $S_{0} \rightarrow S_{1}$ & 592 & 2.09 & $\begin{array}{l}-0.99(147 \rightarrow 148)-0.14(145 \rightarrow 148) \\
0.41\end{array}$
\end{tabular}

Примечание. $\lambda$ - длина волны перехода, $\Delta E-$ энергия перехода, $f-$ сила осциллятора.

Таблица 2. Расчетные электронные свойства открытого и циклического изомеров молекулы ДАЭ1

\begin{tabular}{c|c|c|c|c|c|c|c|c|c|c}
\hline \multicolumn{1}{c|}{ Изомер } & $E_{\mathrm{HOMO}}, \mathrm{eV}$ & $E_{\mathrm{LUMO}}, \mathrm{eV}$ & $I P, \mathrm{eV}$ & $E_{A}, \mathrm{eV}$ & $E_{g}, \mathrm{eV}$ & $\mu, \mathrm{eV}$ & $\eta, \mathrm{eV}$ & $S, \mathrm{eV}$ & $\chi, \mathrm{eV}$ & $\omega, \mathrm{eV}$ \\
\hline Открытый & -6.06 & -2.59 & 6.06 & 2.59 & 3.47 & -4.32 & 1.73 & 0.58 & 4.32 & 5.39 \\
Циклический & -5.46 & -3.02 & 5.46 & 3.02 & 2.44 & -4.24 & 1.22 & 0.82 & 4.24 & 7.36
\end{tabular}

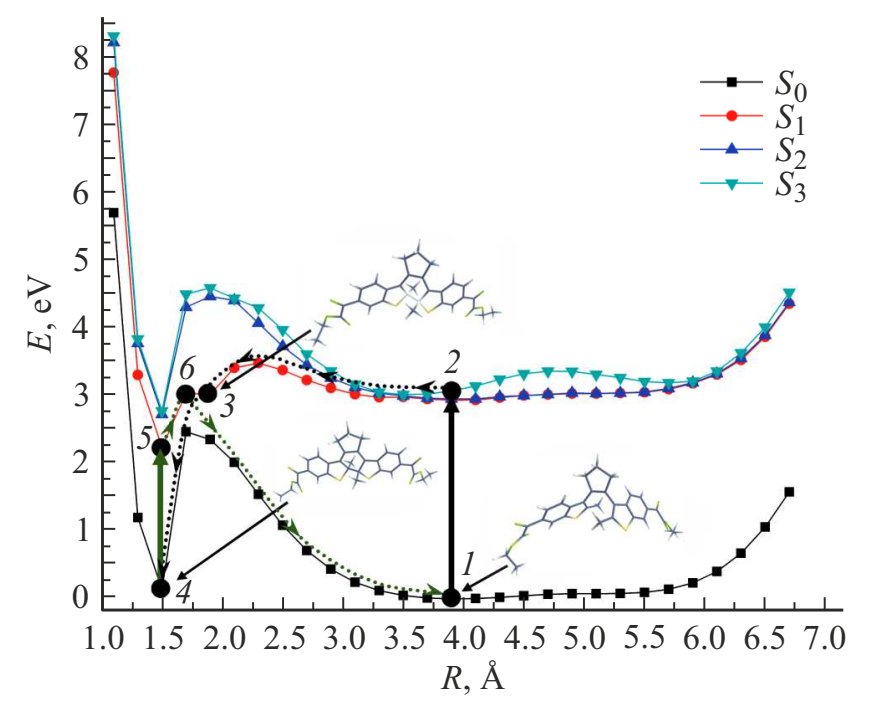

Рис. 3. Сечения поверхностей потенциальной энергии состояний $S_{0}, S_{1}, S_{2}$ и $S_{3}$ молекулы ДАЭ1 и пути прямого (точки 1,2 , $3,4)$ и обратного (точки $4,5,6,1)$ фотохромных превращений.

облучении молекулы ДАЭ1 в длинноволновой полосе поглощения открытой формы А происходит переход $S_{0} \rightarrow S_{3}$, связанный с переносом заряда с алкенового фрагмента и тиофеновых колец (в том числе с атомов серы) на концевые группы молекулы ДАЭ1. При этом переход $S_{0} \rightarrow S_{1}$ имеет близкую нулю вероятность.
Для закрытого (циклического) изомера ДАЭ1 (рис. 2, с и табл. 1) наиболее интенсивные полосы поглощения (с максимумом при $401 \mathrm{~nm}$ и силе осциллятора 0.37 , с максимумом при $592 \mathrm{~nm}$ и силе осциллятора 0.41) относятся к переходам в возбужденные синглетные состояния молекулы: $S_{0} \rightarrow S_{6}, \quad S_{0} \rightarrow S_{1} \quad$ соответственно. Возбуждение электрона с $145 \mathrm{MO}$ на $148 \mathrm{MO}$ дает главный вклад в полосу поглощения при $401 \mathrm{~nm}$; с $147 \mathrm{MO}$ (HOMO) на $148 \mathrm{MO}(\mathrm{LUMO})$ - в полосу поглощения при $592 \mathrm{~nm}$ (рис. 2,d). В результате облучения молекулы ДАЭ1 в длинноволновой полосе поглощения циклической формы $\mathrm{B}$ происходит $\pi-\pi^{*}$-переход $S_{0} \rightarrow S_{1}$, локализованный в алкеновом фрагменте и в тиофеновых и сопряженных с ними кольцах, связанный с перераспределением в этих фрагментах заряда (при этом происходит перенос заряда с атомов серы). Указанное перераспределение заряда приводит к существенному улучшению электропроводности молекулы ДАЭ1, что позволяет рассматривать это соединение как перспективное для применения в фотоуправляемых переключателях электрического сигнала.

При анализе пограничных молекулярных орбиталей соединения ДАЭ1 рассчитаны потенциал ионизации $I P=-E_{\mathrm{HOMO}}, \quad$ сродство к электрону $E_{A}=-E_{\mathrm{LUMO}}$, общая жесткость $\eta=\left(I P-E_{A}\right) / 2$, электроотрицательность $\chi=\left(I P+E_{A}\right) / 2$, электронный химический потен- 
циал $\mu=-\left(I P+E_{A}\right) / 2$, электрофильность $\omega=\chi^{2} / 2 \eta$ и химическая мягкость $S=1 / \eta$.

Результаты анализа пограничных молекулярных орбиталей соединения ДАЭ1 приведены в табл. 2.

Для анализа процессов фотоиндуцированных превращений молекулы ДАЭ1 рассчитаны ППЭ состояний $S_{0}$, $S_{1}, S_{2}, S_{3}$.

Из рис. 3 видно, что в основном состоянии сечение ППЭ молекулы ДАЭ1 имеет два минимума, соответствующие открытой (бесцветной, около $3.9 \AA$ ) и закрытой (циклической, окрашенной, около $1.5 \AA$ ) формам. Стоит отметить, что для открытого изомера наблюдается достаточно широкий минимум, в то время как для циклического изомера он узкий. Данные изомеры разделены барьером по энергии, величина которого составляет $\sim 2.4 \mathrm{eV}$

До УФ облучения молекула ДАЭ1 находится в открытой форме (точка 1 , рис. 3 ), а после фотовозбуждения из состояния $S_{0}$ переходит (с энергией перехода $3.08 \mathrm{eV}$ и силой осциллятора 0.15 ) в состояние $S_{3}$ (точка 2). Затем происходит внутриконверсионный переход $S_{3} \rightarrow S_{1}$, и для того чтобы молекулам перейти в закрытую форму (достичь состояния 4 с минимальной энергией) ей необходимо преодолеть энергетический барьер $\sim 0.5 \mathrm{eV}$. Далее возврат на ППЭ основного состояния $S_{0}$ осуществляется в результате перехода через точку 3 в циклическую форму (точка 4).

При обратном фотохромном превращении ДАЭ1 (из циклической формы в открытую) после фотовозбуждения молекула ДАЭ1 из точки 4 переходит (с энергией перехода $2.09 \mathrm{eV}$ и силой осциллятора 0.41) в возбужденное состояние $S_{1}$ (точка 5). Для того чтобы реакция циклореверсии произошла, система должна достичь точки 6 (около $1.7 \AA$ ) и далее перейти в точку 1 (открытый изомер молекулы ДАЭ1).

\section{Фотоиндуцированные изменения электронных спектров фотохромных наноструктурированных систем на основе ДАЭ1}

Все исследованные нами фотохромные системы на основе неорганических наночастиц и молекул ДАЭ1 испытывают фотоиндуцированные обратимые изменения спектров поглощения. Результаты сравнительного спектрально-кинетического исследования фотохромных превращений ДАЭ1 (в растворе и в твердой фазе) в отсутствие и в присутствии наночастиц серебра и золота представлены в табл. 3 и на рис. 4. Спектр поглощения открытой формы ДАЭ1 в диметилсульфоксиде (ДМСО) характеризуется двумя полосами поглощения с максимумами при 305 и $355 \mathrm{~nm}$ (рис. 4, а, кривая 1, табл. 3). При облучении УФ светом появляется новая полоса поглощения в видимой области спектра с максимумом при $520 \mathrm{~nm}$ (рис. 4, $a$, кривая 2, табл. 3), обусловленная образованием циклической формы В. Это соединение проявляет фотохромные свойства в растворах (в ацетонитриле (АЦН), метаноле, толуоле, ДМСО) как в отсутствие, так и в присутствии золей серебра и золота [26]. После введения в раствор фотохромного соединения наночастиц серебра полосы поглощения открытой формы А ДАЭ1 не смещаются. Светочувствительность $\left(\Delta D_{\mathrm{B}}^{\text {phot }} / D_{\mathrm{A}}\right)$ ДАЭ1 при внесении в раствор наночастиц благородных металлов либо не изменяется (для $\mathrm{Ag}$ ), либо незначительно уменьшается (для $\mathrm{Au}$ ). Кинетические характеристики фотопревращений соединения ДАЭ1 без и в присутствии наночастиц металла не изменяются.

Отсутствие изменений спектрально-кинетических характеристик ДАЭ1 как в растворах, так и в твердофазных слоях при введении наночастиц (табл. 3) можно объяснить тем, что молекулы этого соединения испытывают физическое взаимодействие с поверхностью наночастиц в отличие от хемосорбции, наблюдаемой для функционализированных серосодержащих ДАЭ и проявляющейся в батохромном смещении максимума полосы поглощения циклической формы [45].

ДАЭ1 проявляет фотохромные свойства и в твердофазных пленках, полученных испарением растворителя после нанесения на кварцевую пластинку раствора ДАЭ в АЦН или в ДМСО (рис. 4, $b$ ). Батохромное смещение полосы поглощения циклической формы ДАЭ1, наблюдаемое в твердофазных слоях по сравнению с растворами, возможно обусловлено упорядоченным расположением молекул в твердофазных слоях.

Из табл. 3 и на рис. 4, $c, d$ видно, что наличие наночастиц благородных металлов в твердофазных пленках приводит к незначительному росту величины светочувствительности $\Delta D_{\mathrm{B}}^{\text {phot }} / D_{\mathrm{A}}$ (по сравнению с пленками без наночастиц). Вероятно, это вызвано спецификой взаимодействия молекул ДАЭ с поверхностью наночастиц металла и с вкладом плазмонных эффектов в зависимости от величины перекрывания полосы плазмонного возбуждения наночастиц металла с полосами поглощения исходной открытой $(\mathrm{A})$ и фотоиндуцированной циклической (В) форм ДАЭ1 [26].

Варьируя материал и размеры наночастиц металла, возможно управлять параметрами фотохромных процессов в нанокомпозитах [46]. Кроме того, наличие металлических наночастиц позволяет использовать их в качестве контактов в молекулярных фотоуправляемых переключателях электрического сигнала на основе фотохромных нанокомпозитов, содержащих ДАЭ [4,23].

Для композитных систем „полупроводниковая наночастица-молекулы ДАЭ1“ (содержащих КТ525, люминесцирующие на длине волны $\lambda=525 \mathrm{~nm}$, и ДАЭ1) как в растворах, так и в твердофазных и полимерных пленках обнаружено явление обратимого изменения интенсивности флуоресценции КТ симбатно фотохромным превращениям ДАЭ1 (рис. 5, табл. 4). Это свидетельствует о возможности индуктивно-резонансного переноса энергии возбуждения (FRET) от КТ к циклической форме ДАЭ вследствие перекрывания полосы поглощения фотохрома и полосы флуоресценции КТ и о 

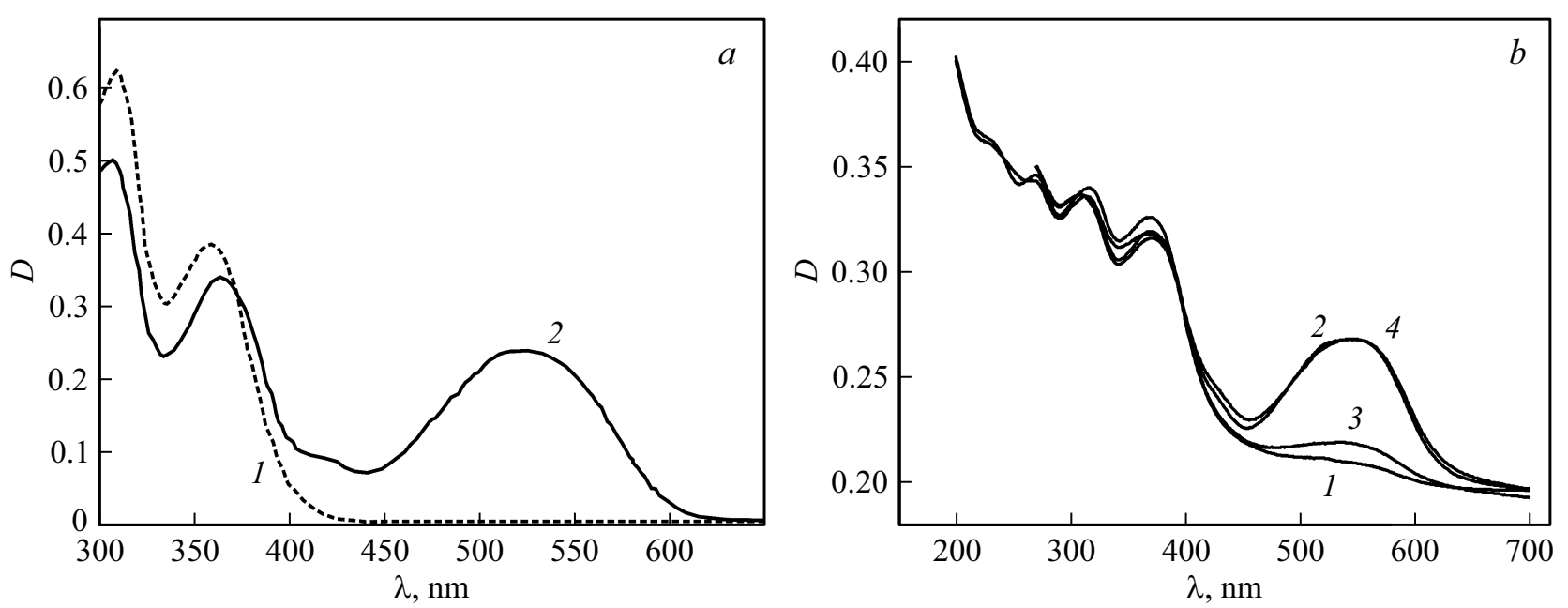

Pис. 4. (а) Спектры поглощения ДАЭ1 в растворах в ДМСО до (кривая 1 ) и после (2) облучения УФ светом лампы LC-4 через светофильтр УФС-1; концентрация ДАЭ в растворе $C=2 \cdot 10^{4} \mathrm{~mol} / \mathrm{dm}^{3}$, толщина кюветы $0.2 \mathrm{~cm}$. $(b)$ Спектры поглощения твердофазных композитных наноструктурированных систем „металлическая наночастица-фотохромная молекула“ $(1,2)$ на основе ДАЭ1 и золей серебра на кварце и твердофазных пленок ДАЭ1 на кварце (без золей, 3,4) до облучения $(1,3)$ и после УФ облучения через светофильтр УФС-1 $(2,4)[26]$.

Таблица 3. Спектральные характеристики фотохромных наноструктурированных систем на основе ДАЭ1 и металлических наночастиц (НЧ)

\begin{tabular}{|c|c|c|c|c|c|}
\hline Система & Состояние & $\lambda_{\mathrm{A}}^{\max }, \mathrm{nm}\left(D_{\mathrm{A}}\right)$ & $\lambda_{\mathrm{B}}^{\max }, \mathrm{nm}$ & $\Delta D_{\mathrm{B}}^{\text {phot }}$ & $\Delta D_{\mathrm{B}}^{\text {phot }} / D_{\mathrm{A}}$ \\
\hline ДАЭ1 & \multirow[t]{2}{*}{ Раствор в ДМСО } & $\begin{array}{l}305(0.61) \\
355(0.40)\end{array}$ & 520 & 0.20 & 0.50 \\
\hline ДАЭ1 + НЧ Ag & & $\begin{array}{l}305(0.62) \\
355(0.40)\end{array}$ & 520 & 0.20 & 0.50 \\
\hline ДАЭ1 & \multirow{2}{*}{$\begin{array}{c}\text { Раствор в смеси } \\
\text { АЦН с водой }(1: 1)\end{array}$} & $\begin{array}{l}308(0.82) \\
354(040)\end{array}$ & 520 & 0.20 & 0.40 \\
\hline ДАЭ1 + НЧ Аu & & $\begin{array}{l}308(0.92) \\
354(0.60)\end{array}$ & 520 & 0.20 & 0.33 \\
\hline ДАЭ1 & \multirow{3}{*}{$\begin{array}{c}\text { Твердофазная } \\
\text { аморфная } \\
\text { пленка }\end{array}$} & $\begin{array}{l}317(0.13) \\
368(0.12)\end{array}$ & 544 & 0.05 & 0.42 \\
\hline ДАЭ1 + НЧ Ag & & $\begin{array}{l}317(0.13) \\
368(0.12)\end{array}$ & 544 & 0.06 & 0.50 \\
\hline ДАЭ1 + НЧ Аu & & $\begin{array}{l}310(0.19) \\
364(0.15)\end{array}$ & 544 & 0.07 & 0.47 \\
\hline
\end{tabular}

Примечание. $\lambda_{\mathrm{A}}^{\max }$ и $\lambda_{\mathrm{B}}^{\max }-$ длины волн максимумов полос поглощения открытой А и циклической В форм соответственно, $D_{\mathrm{A}}-$ максимальное значение оптической плотности в максимуме полосы поглощения открытой формы $\mathrm{A}, \Delta D_{\mathrm{B}}^{\text {phot }}-$ максимальная величина фотоиндуцированной оптической плотности в максимуме длинноволновой полосы поглощения циклической формы В в состоянии фоторавновесия, $\Delta D_{\mathrm{B}}^{\text {phot }} / D_{\mathrm{A}}-$ нормированная фотоиндуцированная оптическая плотность, определяющая светочувствительность соединения.

возможности реализации наноструктурированных регистрирующих сред с недеструктивным флуоресцентным считыванием оптической информации.

Кроме того, изменяя длину волны возбуждения полимерных систем на основе КТ525 и ДАЭ1, можно осуществлять фотопереключение флуоресценции. При этом наблюдается тушение излучения с длиной волны $\lambda=525 \mathrm{~nm}$ с одновременным появлением флуоресцен- ции циклической формы ДАЭ1 в спектральной области с максимумом при $620 \mathrm{~nm}$ (рис. 5, $d$, кривые 4, 5, 6).

Полученные результаты (табл. 4) позволяют сделать выводы о том, что модуляция интенсивности флуоресценции в системе КТ525-ДАЭ1 осуществляется как в растворах, так и в твердотельных пленках. В растворе существенно выше как интенсивность флуоресценции, 

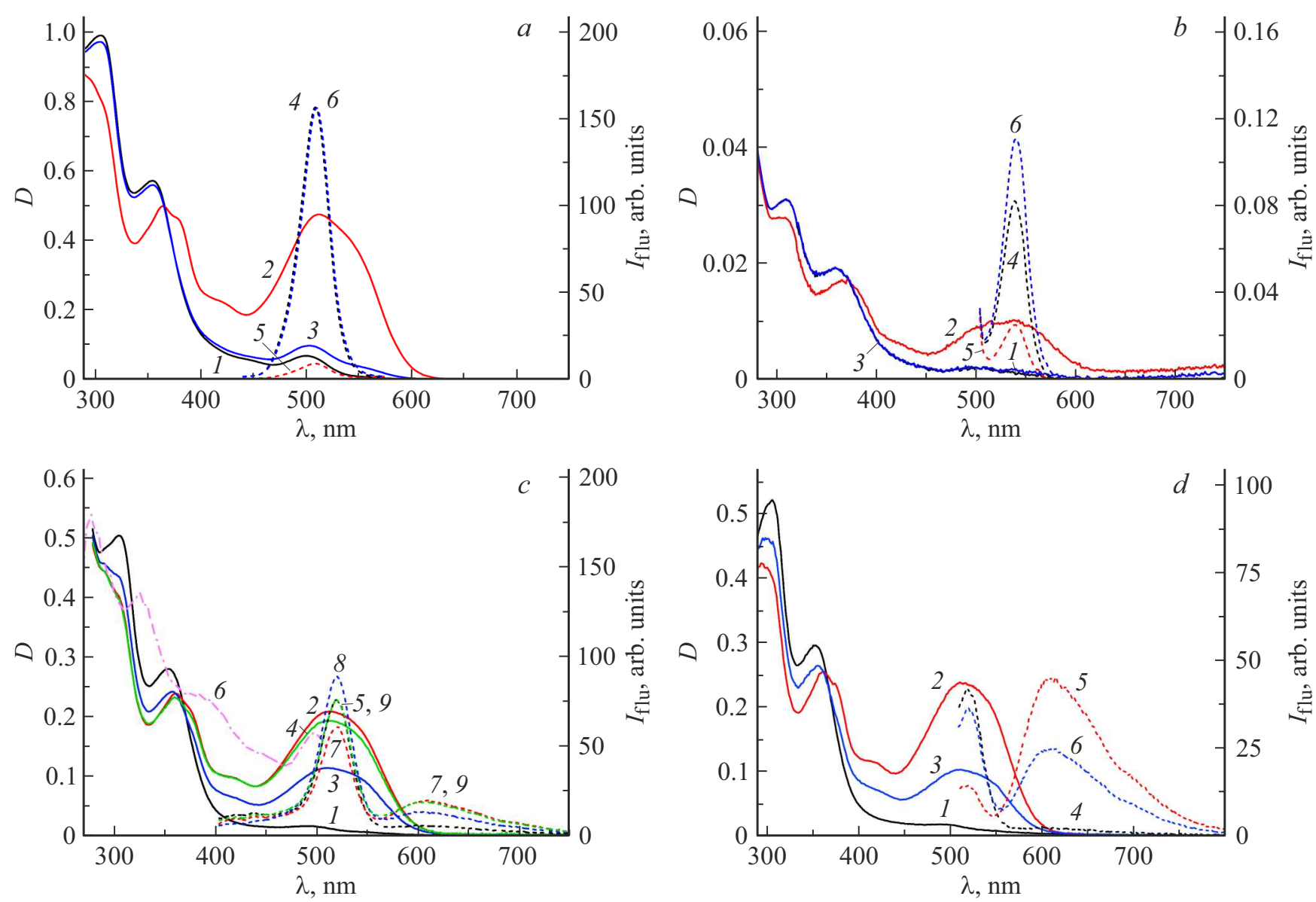

Рис. 5. Спектры поглощения и флуоресценции фотохромной системы КТ525-ДАЭ1 в различных матрицах. (a) Спектры поглощения (кривые 1-3) и флуоресценции на длине волны возбуждения $440 \mathrm{~nm}$ (4-6) системы в толуоле до (1,4), после облучения УФ $(2,5)$ и видимым $(3,6)$ светом. (b) Спектры поглощения $(1-3)$ и флуоресценции на длине волны возбуждения $440 \mathrm{~nm}(4-6)$ твердофазной аморфной пленки системы КТ525-ДАЭ1 до $(1,4)$, после облучения УФ $(2,5)$ и видимым $(3,6)$ светом. (c) Спектры поглощения $(1-4)$, возбуждения флуоресценции при измерении на длине волны $516 \mathrm{~nm}(6)$ и флуоресценции на длине волны возбуждения $395 \mathrm{~nm}(5,7-9)$ системы в полимерной пленке ПММА до $(1,5,6)$, после облучения УФ $(2,7)$ и видимым $(3,8)$ светом и после повторного УФ облучения $(4,9)$. (d) Спектры поглощения $(1-3)$ и флуоресценции на длине волны возбуждения $500 \mathrm{~nm}(4-6)$ системы в полимерной пленке сополимера АС до $(1,4)$, после облучения УФ $(2,5)$ и видимым $(3,6)$ светом.

так и эффективность (глубина) модуляции интенсивности флуоресценции.

Модуляция интенсивности флуоресценции может быть обусловлена изменением квантового выхода флуоресценции КТ вследствие переноса энергии возбуждения и/или заряда на расположенные в непосредственной близости молекулы ДАЭ1, а также эффектом внутреннего фильтра (т.е. поглощением квантов света флуоресценции молекулами ДАЭ1 в закрытой форме В). Используя полученные экспериментальные данные, оценено ослабление интенсивности излучения КТ за счет эффекта внутреннего фильтра. Выявлено, что ослабление излучения за счет указанного эффекта составляет $47 \%$ для комплекса КТ525-ДАЭ1 (в толуоле) при полном обратимом фотоиндуцированном ослаблении флуоресцентного излучения этой системы 94\%. Для выяснения механизма модуляции флуоресценции была исследована зависимость времени затухания флуоресценции КТ при фотоиндуцированных изменениях ДАЭ1. Оказалось, что кинетика затухания флуоресценции исследованных КТ имеет существенно немоноэкспоненциальный характер. Для описания кинетики КТ525 необходимо использовать не менее 3 экспоненциальных компонент с временами жизни $\tau_{1} \sim 2 \mathrm{~ns}, \tau_{2} \sim 7 \mathrm{~ns}$ и $\tau_{3} \sim 18 \mathrm{~ns}$ (для растворов комплексов КТ525-ДАЭ1); $\tau_{1} \sim 0.7 \mathrm{~ns}, \tau_{2} \sim 5 \mathrm{~ns}$ и $\tau_{3} \sim 16 \mathrm{~ns}$ (для твердофазных аморфных пленок комплексов КТ525-ДАЭ1 на кварце); $\tau_{1} \sim 3 \mathrm{~ns}, \tau_{2} \sim 9 \mathrm{~ns}$ и $\tau_{3} \sim 25 \mathrm{~ns}$ (для твердофазных пленок комплексов КТ525ДАЭ1 в полимере ПММА). Предполагается, что образование комплекса КТ525-ДАЭ1 (вследствие специфических взаимодействий между КТ525 и молекулами ДАЭ1 в открытой форме А) приводит к появлению дополнительного безызлучательного канала дезактивации и к некоторому снижению среднего времени жизни возбужденного состояния КТ [30]. 
Таблица 4. Абсорбционные и флуоресцентные характеристики фотохромных наноструктурированных систем на основе ДАЭ1 и KT525 CdSe/ZnS

\begin{tabular}{|c|c|c|c|c|c|c|c|}
\hline Система & Состояние & $\lambda_{\mathrm{A}}^{\max }, \mathrm{nm}\left(D_{\mathrm{A}}\right)$ & $\lambda_{\mathrm{B}}^{\max }, \mathrm{nm}$ & $\Delta D_{\mathrm{B}}^{\text {phot }}$ & $\lambda_{\mathrm{QD}}^{\mathrm{Fl}}, \mathrm{nm}$ & $I_{0}^{\mathrm{Fl}}$, arb. units & $I^{\mathrm{Fl}}$, arb. units \\
\hline ДАЭ 1 & \multirow{2}{*}{$\begin{array}{c}\text { Раствор } \\
\text { в толуоле }\end{array}$} & $357(0.64)$ & 519 & 0.64 & - & - & - \\
\hline ДАЭ 1 + КТ525 & & $355(0.58)$ & 511 & 0.42 & 527 & 156 & 9 \\
\hline ДАЭ 1 & \multirow{2}{*}{$\begin{array}{c}\text { Аморфная } \\
\text { пленка }\end{array}$} & $360(0.03)$ & 519 & 0.10 & - & - & - \\
\hline ДАЭ 1 + КТ525 & & $359(0.02)$ & 536 & 0.009 & 530 & 0.092 & 0.035 \\
\hline ДАЭ 1 & \multirow{2}{*}{$\begin{array}{c}\text { Полимерная } \\
\text { пленка ПММА }\end{array}$} & $358(0.21)$ & 520 & 0.09 & - & - & - \\
\hline ДАЭ $1+$ КТ525 & & $365(0.28)$ & 517 & 0.20 & 523 & 74 & 58 \\
\hline ДАЭ 1 & \multirow{2}{*}{$\begin{array}{c}\text { Полимерная } \\
\text { пленка AC }\end{array}$} & - & - & - & - & - & - \\
\hline ДАЭ 1 + КТ525 & & $352(0.30)$ & 514 & 0.23 & 520 & 41 & 14 \\
\hline
\end{tabular}

Примечание. $\lambda_{\mathrm{A}}^{\max }, \lambda_{\mathrm{B}}^{\max }$ - длины волн максимумов полос поглощения исходной открытой и фотоиндуцированной циклической формы ДАЭ, $\lambda_{\mathrm{QD}}^{\mathrm{Fl}}$ - длина волны максимума полосы флуоресценции КT; $\Delta D_{\mathrm{B}}^{\text {phot }}$ - фотоиндуцированное изменение оптической плотности в максимуме полосы поглощения фотоиндуцированной циклической формы ДАЭ в состоянии фоторавновесия; $I_{0}^{\mathrm{Fl}}, I^{\mathrm{Fl}}-$ интенсивности полос флуоресценции КТ до и после УФ облучения соответственно.
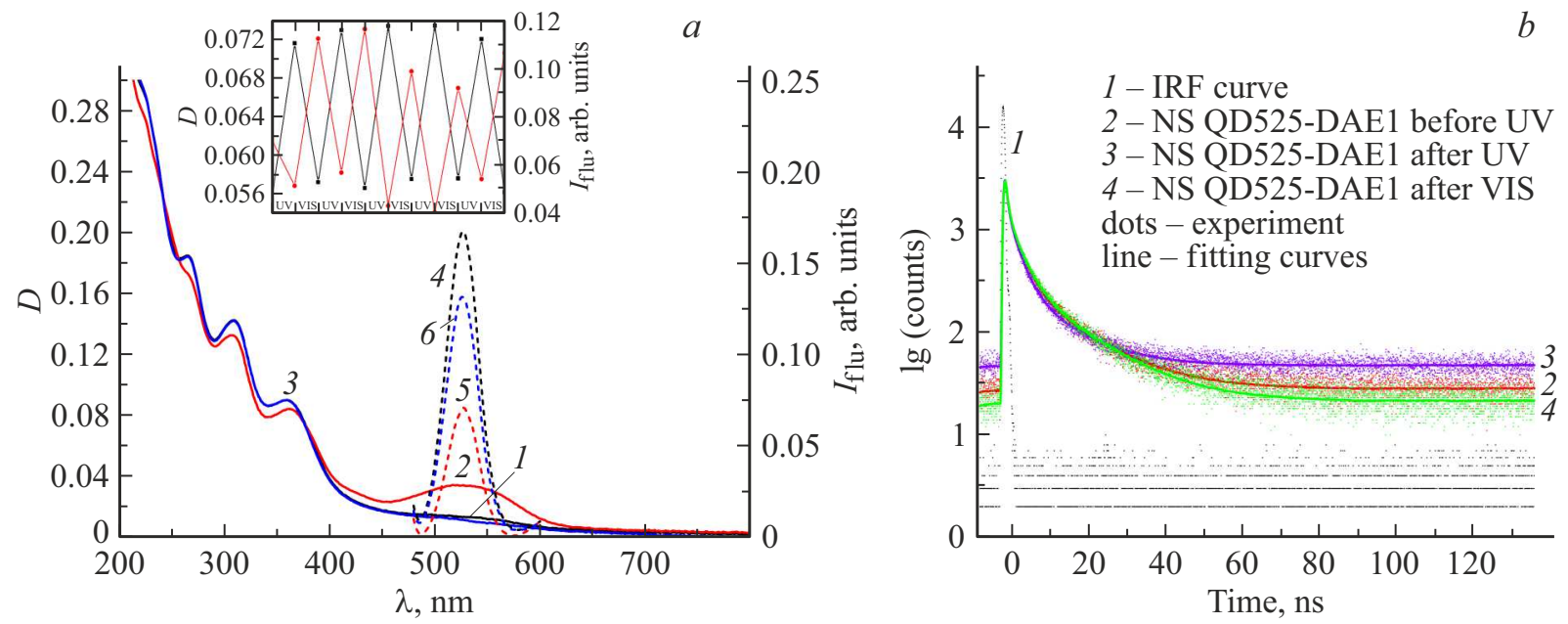

Рис. 6. (а) Спектры поглощения (кривые 1-3) и флуоресценции на длине волны возбуждения $500 \mathrm{~nm}(4-6)$ полимерных наносфер, содержащих КТ525 и ДАЭ1, в воде до $(1,4)$, после облучения УФ $(2,5)$ и видимым $(3,6)$ светом. На вставке показано изменение оптической плотности (черные кривые) на длине волны $532 \mathrm{~nm}$ и интенсивности флуоресценции (красные) на длине волны $525 \mathrm{~nm}$ полимерных наносфер, содержащих КТ525 и ДАЭ1, после последовательного облучения УФ $(\lambda=365 \mathrm{~nm}, t=150 \mathrm{~s})$ и видимым $(\lambda=514 \mathrm{~nm}, t=150 \mathrm{~s})$ светом. $(b)$ Кривые затухания флуоресценции водных растворов наносфер, содержащих ДАЭ1 до $(b, 2)$, после УФ $(b, 3)$ и после видимого $(b, 4)$ облучения.

Полученные результаты (табл. 5) показывают, что обратимая фотоизомеризация ДАЭ1 вследствие УФ и видимого облучения значительно влияет на время жизни флуоресценции КТ, что предполагает значительный вклад механизма FRET в модуляцию интенсивности флуоресценции КТ.

В случае полимерных пленок, в отличие от трех других матриц (табл. 5), обратимая модуляция (с существенной глубиной модуляции) наблюдается только для среднего времени жизни $\left\langle\tau^{\alpha}\right\rangle$ по амплитуде (но не для $\langle\tau\rangle)$. Это может быть связано с тем, что в пленке ПММА может возрастать гетерогенность излучающих центров вследствие взаимодействий молекул полимера с системами КТ-ДАЭ1. Тогда правильнее оценивать кинетику затухания свечения КТ не по среднему времени жизни $\langle\tau\rangle$ по вкладу

$$
\langle\tau\rangle=\frac{\sum_{i} \alpha_{i} \tau_{i}^{2}}{\alpha_{i} \tau_{i}}
$$

а по среднему времени жизни $\left\langle\tau^{\alpha}\right\rangle$ по амплитуде

$$
\left\langle\tau^{\alpha}\right\rangle=\frac{\sum_{i} \alpha_{i} \tau_{i}}{\alpha_{i}}
$$


Таблица 5. Среднее время жизни $\langle\tau\rangle$ по вкладу и среднее время жизни $\left\langle\tau^{\alpha}\right\rangle$ по амплитуде флуоресценции КТ525 в процессе фотохромных превращений ДАЭ1 в различных системах

\begin{tabular}{l|c|c|c|c|c|c}
\hline Система (состояние) & $\left\langle\tau_{0}\right\rangle, \mathrm{ns}$ & $\left\langle\tau_{\mathrm{UV}}\right\rangle, \mathrm{ns}$ & $\left\langle\tau_{\mathrm{VIS}}\right\rangle, \mathrm{ns}$ & $\left\langle\tau_{0}^{\alpha}\right\rangle, \mathrm{ns}$ & $\left\langle\tau_{\mathrm{UV}}^{\alpha}\right\rangle, \mathrm{ns}$ & $\left\langle\tau_{\mathrm{VIS}}^{\alpha},, \mathrm{ns}\right.$ \\
\hline Раствор в толуоле & 12.93 & 11.99 & 12.84 & 9.29 & 7.73 & 9.29 \\
\hline Твердофазная аморфная пленка & 9.66 & 7.38 & 10.00 & 4.00 & 2.47 & 4.35 \\
\hline Полимерная ПММА пленка & 11.84 & 11.96 & 11.96 & 8.10 & 6.63 & 8.80 \\
\hline Полимерные наносферы & 7.05 & $5.39^{*}$ & $7.42^{* *}$ & 2.08 & $1.66^{*}$ & $2.11^{* *}$
\end{tabular}

Примечание. $\left\langle\tau_{0}\right\rangle\left(\left\langle\tau_{0}^{\alpha}\right\rangle\right),\left\langle\tau_{\mathrm{UV}}\right\rangle\left(\left\langle\tau_{\mathrm{UV}}^{\alpha}\right\rangle\right),\left\langle\tau_{\mathrm{VIS}}\right\rangle\left(\left\langle\tau_{\mathrm{VIS}}^{\alpha}\right\rangle\right)$ - времена жизни КТ525 до, после УФ облучения в течение $15 \mathrm{~s}$ и после облучения видимым светом $(\lambda=514 \mathrm{~nm})$ в течение $30 \mathrm{~s}$ соответственно. Для полимерных наносфер время облучения УФ светом $20 \mathrm{~s}^{*}$ и видимым светом $45 \mathrm{~s}^{* *}$.

где $\alpha_{i}, \tau_{i}-$ предэкспоненциальный множитель и время жизни $i$-й компоненты соответственно.

Подобные спектрально-кинетические исследования также проведены для синтезированных полимерных наносфер, содержащих КТ525 и молекулы ДАЭ1. Фотоиндуцированная изомеризация молекул ДАЭ1 влияет на параметры флуоресценции КТ525 в наносферах (рис. 6, табл. 5). По оценкам снижение интенсивности свечения наносфер за счет изменения квантового выхода флуоресценции КТ составляет 53\%. Влияние эффекта внутреннего фильтра не превышает 3\%, что свидетельствует об эффективности применения разработанных фотохромных наносфер по сравнению с ранее описанными наноструктурированными системами [30,31]. Для выяснения механизма тушения флуоресценции КТ молекулами ДАЭ1 в наносферах была исследована кинетика затухания флуоресценции КТ при фотоиндуцированном изменении ДАЭ1 (рис. $6, b$, табл. 5).

Выявлено, что кривая затухания удовлетворительно аппроксимируется тремя экспонентами с временами жизни $\tau_{1} \sim 0.5 \mathrm{~ns}, \tau_{2} \sim 3 \mathrm{~ns}$ и $\tau_{3} \sim 14 \mathrm{~ns}$. Наблюдаемые изменения интенсивности флуоресценции КТ вследствие фотопревращений молекул ДАЭ1 повторяются и в обратимом изменении значений их длительности флуоресценции. Сокращение длительности $\langle\tau\rangle$ флуоресценции наносфер после УФ облучения восстанавливается полностью после облучения видимым светом. Поэтому можно утверждать, что FRET является механизмом, определяющим модуляцию интенсивности флуоресценции КТ в синтезированных наносферах при обратимой фотоизомеризации имплантированных в них молекул ДАЭ1.

\section{Моделирование FRET}

Для оценивания параметров наноструктурированной системы „КТ525-ДАЭ1“, оптимальных для осуществления процесса FRET, проведено компьютерное моделирование этой системы.

На основании спектральных данных для комплексов КТ525 с молекулами ДАЭ1 в соответствии с известными моделями [30,31] рассчитано значение критического радиуса Фёрстера $R_{01}=5.60 \mathrm{~nm}$ (при значениях коэффициента ориентации пары диполей донор-акцептор $\kappa^{2}=0.67$, показателя преломления $n_{\text {ref }}=1.4969$, квантового выхода флуоресценции КТ $\Phi=0.628$ ).

Для полимерных наносфер на основе значений молярного коэффициента поглощения (для ДАЭ1 в толуоле с $\lambda=370 \mathrm{~nm} \varepsilon=1.33 \cdot 10^{4} \mathrm{M}^{-1} \mathrm{~cm}^{-1}$ и для КТ $\mathrm{CdSe}$ диаметром $2.7 \mathrm{~nm} \varepsilon=5 \cdot 10^{4} \mathrm{M}^{-1} \mathrm{~cm}^{-1}$ [47]) рассчитано среднее количество молекул ДАЭ1 на одну КТ в наноcфере: $n \sim 4-8$. Согласно оценке, доля фотоиндуцированной формы В молекул ДАЭ1 в состоянии равновесия форм А и В составляет около 30\%. При значениях коэффициента ориентации пары диполей донор-акцептор $\kappa^{2}=0.48$, показателя преломления $n_{\text {ref }}=1.50$, квантового выхода флуоресценции КТ $\Phi=0.0628$ значение критического радиуса Фёрстера для полимерных наносфер составляет $R_{02}=3.60 \mathrm{~nm}$.

Посредством моделирования оценена эффективность FRET при различных соотношениях количества молекул ДАЭ1, приходящихся на одну КТ. Эффективность FRET для донора D (KT) в окружении n молекул акцептора A (ДАЭ1) по результатам измерения длительности флуоресценции [31]

$$
E(\tau)=1-\frac{\tau_{\mathrm{D} A n}}{\tau_{\mathrm{D}}},
$$

$\tau_{\mathrm{DA} n}-$ время жизни возбужденного состояния донора в присутствии акцептора,

$$
\frac{1}{\tau_{\mathrm{DA} n}}=\frac{1}{\tau_{\mathrm{D}}} \prod_{i=1}^{n}\left(1+\left(\frac{R_{0}}{r_{i}}\right)^{6}\right),
$$

$\tau_{\mathrm{D}}$ - время жизни возбужденного состояния донора в отсутствие акцептора, $R_{0}$ - радиус Фёрстера, $r_{i}$ расстояние между $i$-й молекулой акцептора и донором.

Результаты расчета зависимостей эффективности модуляции флуоресценции КТ-ДАЭ1 от расстояния $r$ между КТ и ДАЭ1, от количества $n$ молекул ДАЭ1 на КТ, от квантового выхода флуоресценции КТ $(\Phi=0.6$ для раствора, $\Phi=0.06$ для полимерных наносфер) и от процентного содержания молекул окрашенной формы ДАЭ1 приведены на рис. 7.

При фиксированном значении $R_{0}$ эффективность тушения флуоресценции КТ за счет переноса энергии на окрашенные фотоизомеры ДАЭ1 зависит от расстояния 

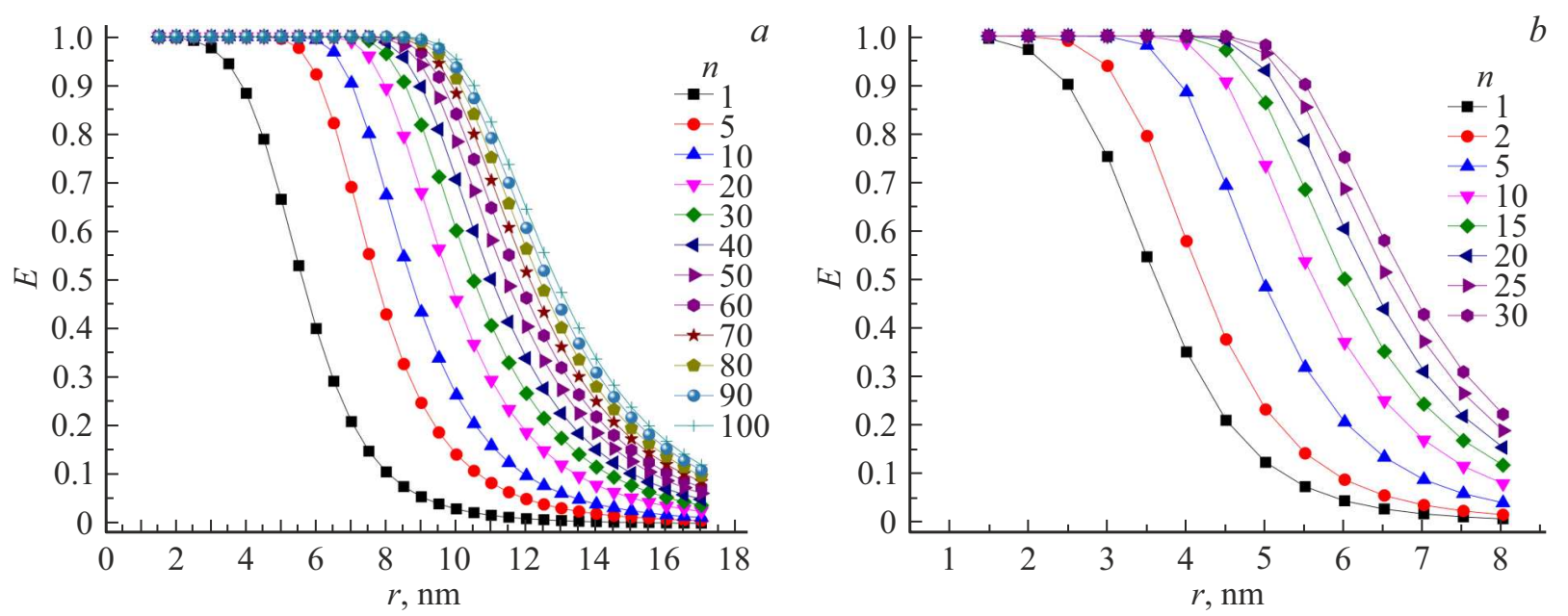

Рис. 7. Зависимость эффективности модуляции флуоресценции КТ-ДАЭ1 (в растворе $(a)$ и в полимерных наносферах $(b))$ от расстояния $r$ между КТ и ДАЭ1 и от количества $n$ молекул ДАЭ1 на КТ (при $30 \%$ молекул окрашенной формы ДАЭ1).
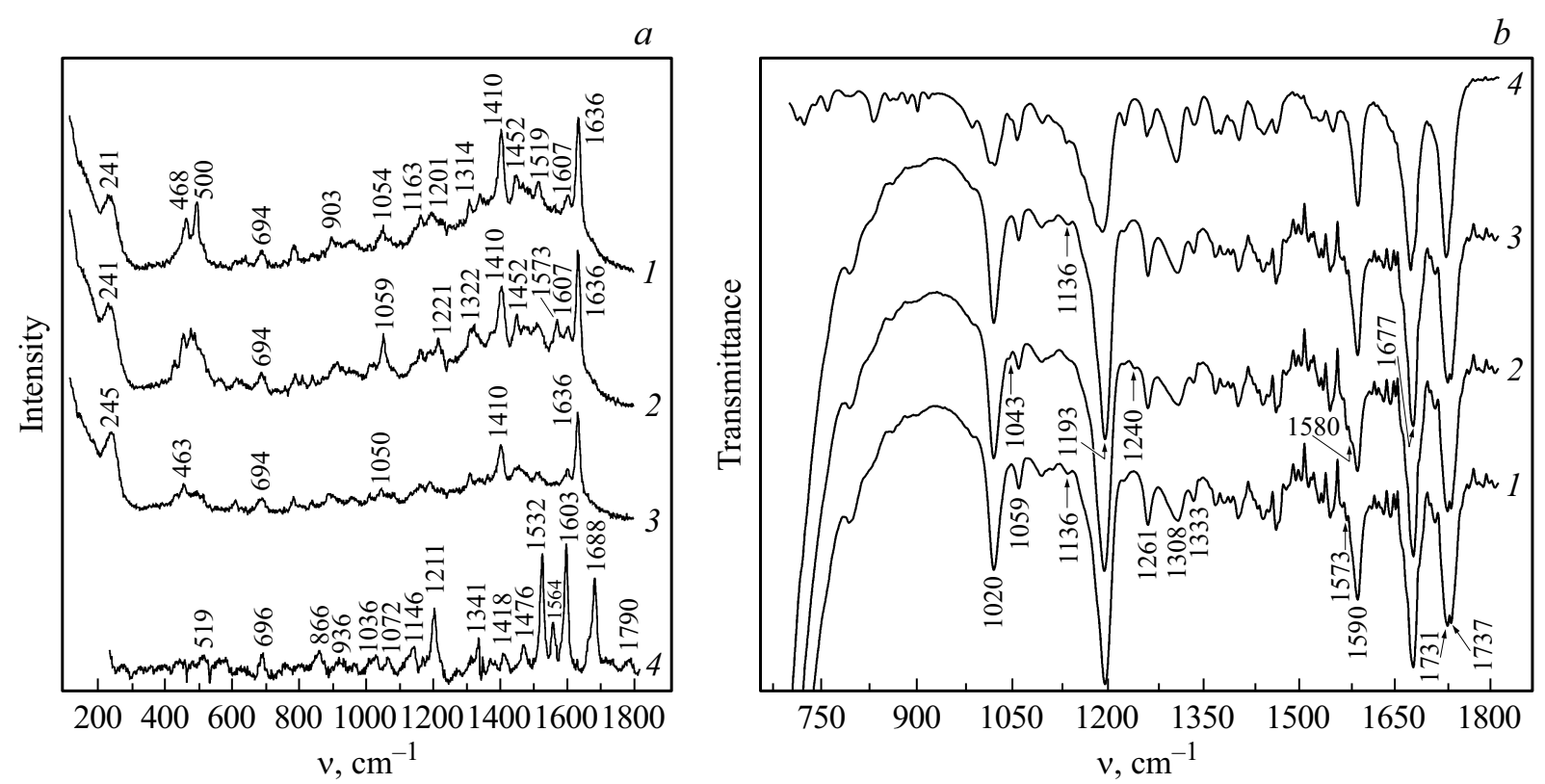

Рис. 8. Спектры КР света ( $a$, кривая 4) и ИК поглощения $(b, 4)$ порошка ДАЭ1. Спектры ГКР света $(a, 1-3)[28]$ твердофазных композитных наноструктур „металлическая наночастица-фотохром“ (на основе соединения ДАЭ1 и золя серебра на кварцевой подложке) при $\lambda_{\mathrm{ex}}=633 \mathrm{~nm}$ : до облучения $(a, 1)$, после УФ облучения $(a, 2)$, после последующего облучения лазерным излучением с длиной волны $\lambda=633 \mathrm{~nm}(a, 3)$. Твердофазные композитные наноструктуры получены из растворов в метаноле. Спектры ИК поглощения $(b, 1-3)$ пленки ДАЭ1 из толуольного раствора: до облучения $(b, 1)$, после УФ облучения $(b, 2)$, после последующего облучения видимым светом $(b, 3)$.

между донором (КТ525) и акцептором (молекула ДАЭ1) энергии, а также от количества акцепторов в окружении одного донора.

Из рис. 7 видно, что высокие значения $(\sim 0.8)$ коэффициента тушения флуоресценции доноров достигаются при расстояниях $r$ между донорами и акцепторами в пределах $6.5 \mathrm{~nm}$, если на одну КТ с квантовым выходом флуоресценции в комплексе $60 \%$ приходится не менее 5 молекул ДАЭ1 (в растворе), либо при $r=4 \mathrm{~nm}$, если на одну КТ с квантовым выходом флуоресценции в комплексе 6\% приходится не менее 5 молекул ДАЭ1 (в полимерных наносферах).

Из анализа полученных результатов (рис. 7,b) можно оценить значение расстояния $r \sim 4 \mathrm{~nm}$ между КТ и ДАЭ1 при следующих значениях параметров: 30\% молекул окрашенной формы ДАЭ1, квантовый выход флуоресценции КТ $\Phi=0.06$, радиус Фёрстера $R_{02}=3.60 \mathrm{~nm}$, среднее количество молекул ДАЭ1 на одну КТ в наносфере примерно $n \sim 6$ и глубина (эф- 
$a$

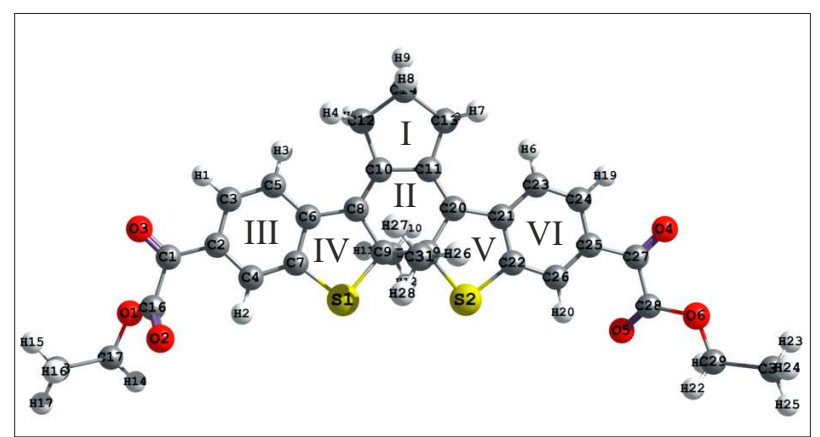

$c$

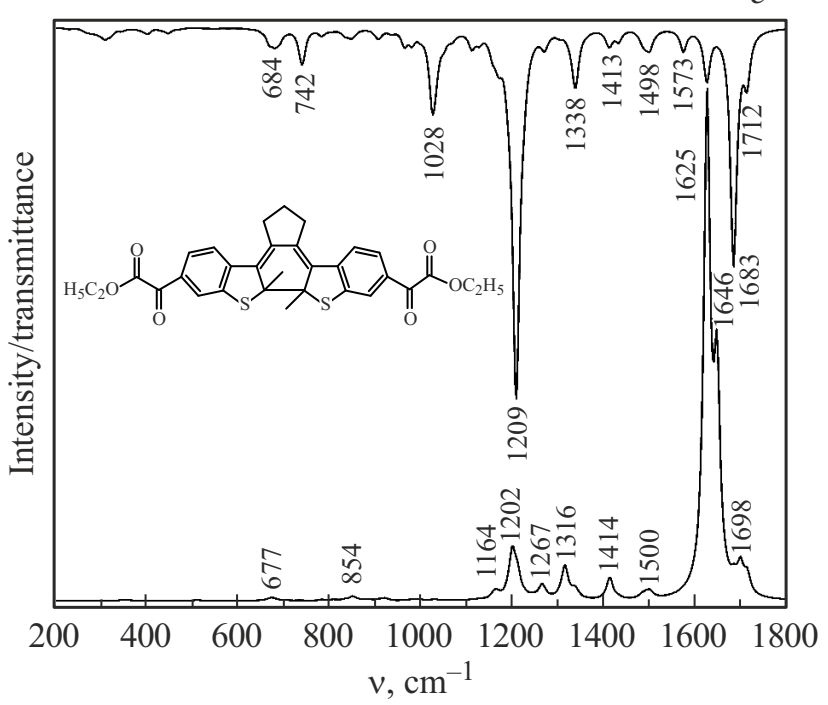

$b$

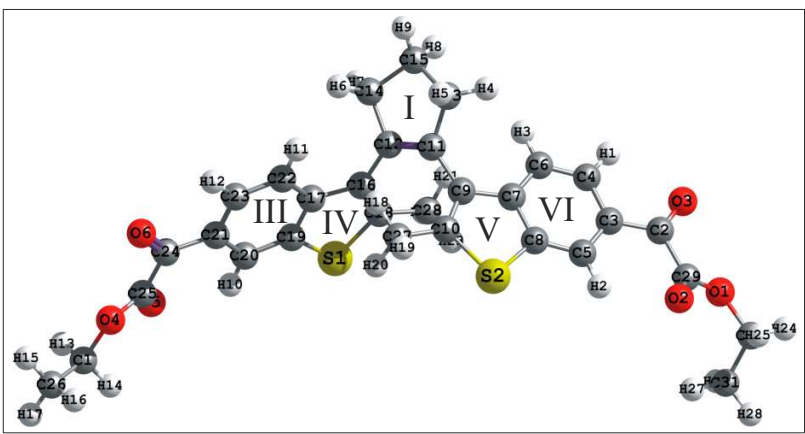

西

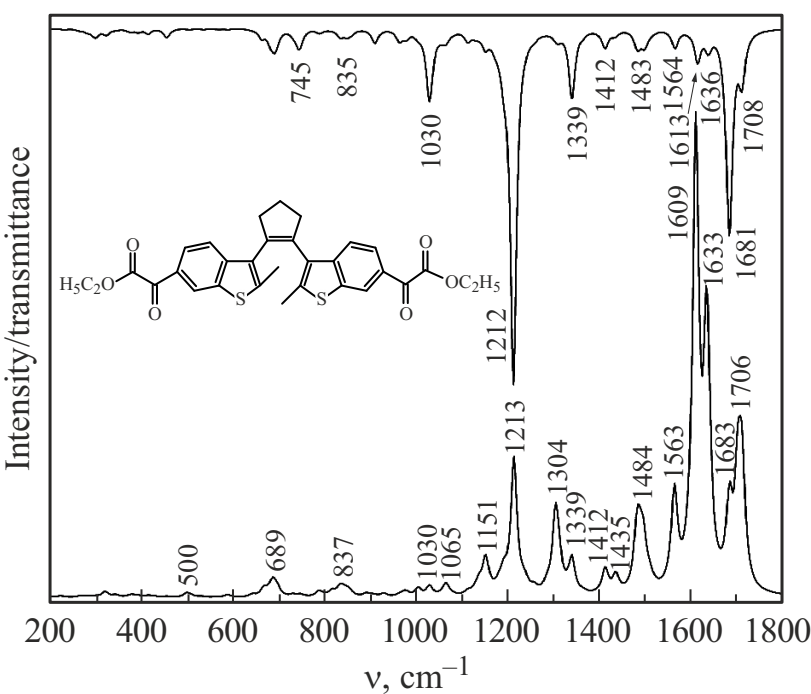

Рис. 9. Оптимизированная геометрия циклической $(a)$ и открытой $(b)$ форм молекулы ДАЭ1. Рассчитанные зависимости интенсивности ИК поглощения (верхние графики) и активности КР (нижние графики) от частоты циклической $(c)$ и открытой $(d)$ форм молекулы ДАЭ1.

фективность) модуляции интенсивности флуоресценции наносфер $\sim 0.57$.

\section{Фотоиндуцированные изменения колебательных спектров фотохромных систем на основе ДАЭ1}

Фотоиндуцированные обратимые изменения структуры фотохромных молекул в различных матрицах могут проявляться (наряду со спектрами электронного поглощения) также и в колебательных спектрах.

Экспериментальные спектры ИК поглощения и КР света ДАЭ1 в порошке, а также спектры ГКР света исследуемых нанокомпозитных систем на основе этого ДАЭ (и спектры ИК поглощения твердофазных пленок ДАЭ1) и их фотоиндуцированные изменения в процессе фотохромных превращений молекул показаны на рис. 8.

Квантово-химическими методами (с использованием оптимизированных для данных задач расчетных методов и базисов) получены уточненные данные по структуре и колебательным спектрам фотохромной молекулы
ДАЭ1 в открытой А и циклической В формах (рис. 9). C применением этих данных проведена интерпретация экспериментальных колебательных спектров (ИК, КР и ГКР). В расчетных спектрах наиболее интенсивны полосы, обусловленные плоскими колебаниями связанных циклов. При этом для циклической формы, имеющей планарную конфигурацию, между циклами имеет место $\pi$-сопряжение. В результате фотоиндуцированной реакции циклореверсии происходит разрыв С9-С19-связи, вследствие чего плоскости циклов III, IV и циклов V, VI молекулы ДАЭ1 поворачиваются друг относительно друга на угол около 70. При этом интенсивность полос КР снижается на порядок.

Наибольшая интенсивность в экспериментальных спектрах как ИК поглощения, так и КР (ГКР) света ДАЭ1 наблюдается для полос, относящихся к плоским валентным и деформационным колебаниям (около 500, $1200,1410,1607,1636 \mathrm{~cm}^{-1}$ - ГКР и около 1020 , 1193, 1590, 1677, $1733 \mathrm{~cm}^{-1}$ - ИК спектры). Полосы около $1200,1600,1680 \mathrm{~cm}^{-1}$ интенсивны как в спектрах ИК поглощения, так и КР (ГКР) света. Это объясня- 
ется близостью значений вероятностей колебательных переходов благодаря специфике локальной симметрии молекул [28]. Наибольшее усиление испытывают полосы КР около 500, 1410, $1636 \mathrm{~cm}^{-1}$, основной вклад в которые вносят плоские колебания, что проявляется в спектрах ГКР твердофазных композитных наноструктур „металлическая наночастица-фотохром“ (рис. 8, $a$, кривые $1-3)$. Гладкая сфероидальная форма наночастиц серебра (без мелких шероховатостей с резкими изломами поверхности), а также их размеры позволяют полагать, что в усиление сигнала КР молекул ДАЭ1, адсорбированных на этих частицах, наибольший вклад вносят плазмонные механизмы, а не другие электромагнитные механизмы усиления, например связанные с гигантским возрастанием электромагнитных полей и их градиентов на изломах поверхности с малыми радиусами кривизны [48].

Фотопревращения композитных наноструктур „металлическая наночастица-фотохром“ проявляются в изменении относительной интенсивности полос в колебательных спектрах соединения ДАЭ1, относящихся к колебаниям связи, участвующей в реакции фотоизомеризации [28]. Последовательное облучение образца сначала УФ, а затем видимым светом приводит вначале к возрастанию относительной интенсивности полос около 1221 и $1573 \mathrm{~cm}^{-1}$ (рис. 8, $a$, кривая 2), а потом к возврату формы спектра ГКР к исходной (рис. 8, $a$, кривые 1,3). В этих спектральных изменениях проявляются фотохромные свойства данного нанокомпозита. Обратимые изменения относительной интенсивности полос, относящихся к колебаниям связи $\mathrm{C}_{9}-\mathrm{C}_{19}$, наблюдаются и в спектре ИК поглощения (полосы около 1043, 1240 , $\left.1580 \mathrm{~cm}^{-1}\right)$.

Важным свидетельством химического взаимодействия молекулы ДАЭ1 с поверхностью металла является наличие полосы около $240 \mathrm{~cm}^{-1}$ (обусловленной колебанием связи молекула-металл [49]) в спектрах ГКР нанокомпозитов на основе соединения ДАЭ1, полученных из раствора в метаноле (рис. 8, $a$, кривые $1-3$ ), в отличие от аналогичных нанокомпозитов, полученных из раствора в ацетонитриле [28].

\section{Выводы}

Изучены спектральные свойства созданных композитных наноструктур „наночастица-фотохромная молекула“, состоящих из наночастиц $\mathrm{Ag}, \mathrm{Au}$ (или КТ) с оболочкой из молекул фотохромного ДАЭ. Обнаружено, что данные нанокомпозиты как в растворах, так и в твердофазных слоях обладают фотохромными свойствами (которые проявляются в обратимых фотоиндуцированных изменениях электронных и колебательных спектров ДАЭ), подобные фотохромным превращениям ДАЭ в растворах и в твердофазных слоях, не содержащих наночастиц.
Квантово-химическое исследование электронных и колебательных спектров и получение сечений поверхностей потенциальной энергии ДАЭ1 позволили оценить числовые параметры структуры, энергии и электронных свойств при фотоизомеризации молекулы ДАЭ1.

Фотоиндуцированное изменение структуры нанокомпозитов „металлическая наночастица-фотохром“ проявляется в изменении относительных интенсивностей полос в спектрах ГКР и ИК, в первую очередь полос, обусловленных валентными колебаниями связи $\mathrm{C}_{9}-\mathrm{C}_{19}$, участвующей в реакции обратимой фотоизомеризации ДАЭ.

По результатам моделирования процесса индуктивнорезонансного переноса энергии возбуждения между KT $\mathrm{CdSe} / \mathrm{ZnS}$ и фотохромными молекулами созданы фотоуправляемые флуоресцентные системы КТ525ДАЭ1. Системы КТ525-ДАЭ1 как в растворах, так и в твердотельных слоях, а также в полимерных наносферах проявляют модуляцию интенсивности и длительности флуоресценции КТ вследствие обратимой фотоизомеризации молекул фотохромного соединения. Наблюдаемая модуляция интенсивности флуоресценции в этих системах обусловлена как индуктивно-резонансным переносом энергии от КТ к фотоиндуцированной циклической форме молекул ДАЭ (FRET) (по оценкам $\sim 47 \%$ для растворов комплексов КТ525-ДАЭ1, $\sim 53 \%$ для полимерных наносфер), так и эффектом перепоглощения флуоресценции фотохромными молекулами (по оценкам $\sim 47 \%$ для растворов комплексов КТ525-ДАЭ1, $\sim 3 \%$ для полимерных наносфер), что значительно лучше ранее полученных нами результатов для других ДАЭ [30,31].

Посредством моделирования определены критические радиусы Фёрстера для пары КТ525-ДАЭ1 $\left(R_{01}=5.60 \mathrm{~nm}\right.$ в растворах и $R_{02}=3.60 \mathrm{~nm}$ в полимерных наносферах) и эффективность FRET при различных соотношениях количества молекул ДАЭ1 на одну КТ.

Получены композитные наноструктурированные элементы на основе фотохромного ДАЭ1, обратимо изменяющие под действием света абсорбционные и флуоресцентные свойства в соответствии с фотохромными превращениями ДАЭ, которые могут быть использованы при разработке оптико-электронных фотоуправляемых молекулярных переключателей, а также био- и хемосенсоров.

\section{Благодарности}

Авторы выражают искреннюю благодарность В.И. Степуро и А.Г. Старикову за участие в обсуждении представленных в работе результатов.

\section{Финансирование}

Работа выполнена при финансовой поддержке БРФФИ (грант № Ф21РМ-134), Министерства образования 
Республики Беларусь (задание 1.5 ГПНИ, Фотоника и электроника для инноваций“) и Министерства науки и высшего образования РФ в рамках выполнения работ по Государственному заданию ФНИЦ „Кристаллография и фотоника“ РАН в части анализа спектральных свойств фотохромных систем.

\section{Конфликт интересов}

Авторы заявляют, что у них нет конфликта интересов.

\section{Список литературы}

[1] C. Joachim, J.K. Gimzewski, A.A. Aviram. Nature, 408, 541 (2000). DOI:10.1038/35046000

[2] R.L. Carroil, C.B. Gorman. Angew. Chem. Int. Ed., 41, 4378 (2002). DOI: 10.1002/1521-3773(20021202)41:23<4378:: AID-ANIE4378>3.0.CO;2-A

[3] M. Irie. Molecular switches, ed. by B.L. Feringa (Wiley-VCH, Weinheim, 2001), ch. 5, p. 37-60.

[4] M. Irie, T. Fukaminato, K. Matsuda, S. Kobatake. Chem.Rev., 114, 12174 (2014). DOI: 10.1021/cr500249p

[5] H. Tian, S. Yang. Chem. Soc. Rev., 33, 85 (2004). DOI: $10.1039 / \mathrm{B} 302356 \mathrm{G}$

[6] Molecular switches, ed. by B.L. Feringa (Wiley-VCH, Weinheim, 2001).

[7] V.A. Barachevsky. Org. Photon. Photovolt., 3 (1), 8 (2015). DOI: 10.1515/oph-2015-0003

[8] H. Yamaguchi, M. Ikeda, K. Matsuda, M. Irie. Bull. Chem. Soc. Jpn., 79, 1413 (2006). DOI: 10.1246/bcsj.79.1413

[9] T. Kubernac, S.J. Molen, B.J. Wees, B.L. Feringa. Chem. Commun., 3597 (2006). DOI: 10.1039/B609119A

[10] N. Katsonis, T. Kubernac, M. Walko. Adv. Mater., 18, 1397 (2006). DOI: 10.1002/adma.200600210

[11] S. Perrier, F. Maurel, J. Aubard. J. Phys. Chem. A., 111, 9688 (2007). DOI: $10.1021 / \mathrm{jp} 073436 \mathrm{a}$

[12] B.L. Feringa. J. Org. Chem., 72, 6635 (2007). DOI: 10.1021/jo070394d

[13] K. Matsuda, H. Yamaguchi, T. Sakano, M. Ikeda, N. Tanifuji, M. Irie. J. Phys. Chem. C., 112, 17005 (2008). DOI:10.1021/jp807479g

[14] H. Nishi, T. Asahi, S. Kobatake. J. Phys. Chem. C, 113, 17359 (2009). DOI: $10.1021 / \mathrm{jp} 906371 \mathrm{k}$

[15] H. Yamaguchi, K. Matsuda, M. Irie. J. Phys. Chem. C, 111, 3853 (2007). DOI:10.1021/jp065856q

[16] M. Ikeda, N. Tanifuji, H. Yamaguchi, M. Irie, K. Matsuda. Chem. Commun., 13, 1355 (2007). DOI: 10.1039/B617246F

[17] M.-S. Wang, G. Xu, Z.-J. Zhang, G.-C. Guo. Chem. Commun., 46, 361 (2010). DOI:10.1039/B917890B

[18] A. Nitzan, L.E. Brus. J. Chem. Phys., 74, 5321 (1981). DOI: $10.1063 / 1.441699$

[19] A. Nitzan, L.E. Brus. J. Chem. Phys., 75, 2205 (1981). DOI: $10.1063 / 1.442333$

[20] K. Watanabe, D. Menzel, N. Nilius, H.-J. Freund. Chem. Rev., 106 (10), 4301 (2006). DOI: 10.1021/cr050167g

[21] K. Ueno, H. Misawa. J. Photochem. Photobiol. C, 15, 31 (2013). DOI: 10.1016/j.jphotochemrev.2013.04.001

[22] G.T. Vasilyuk, S.A. Maskevich, A.E. German, I.F. Sveklo, B.S. Luk'yanov, L.A. Ageev. High Ener. Chem., 43 (7), 521 (2009). DOI: $10.1134 / S_{0} 018143909070017$
[23] R. Klajn, J.F. Stoddart, B.A. Grzybowski. Chem. Soc. Rev., 39, 2203 (2010). DOI: 10.1039/B920377J

[24] J. Zhang, Q. Zou, H. Tian. Adv. Mater., 25, 378 (2013). DOI:10.1002/adma.201201521

[25] J. Cusido, E. Deniz, F.M. Raymo. Eur. J. Org. Chem., (13), 2031 (2009). DOI: 10.1002/ejoc.200801244

[26] Г.Т. Василюк, В.Ф. Аскирка, А.Е. Герман, И.Ф. Свекло, В.М. Ясинский, А.А. Ярошевич, О.И. Кобелева, Т.М. Валова, А.О. Айт, В.А. Барачевский, В.Н. Яровенко, М.М. Краюшкин, С.А. Маскевич. Журн. прикл. спектроск., 84 (4), 570 (2017). [J. Appl. Spectrosc., 84 (4), 588 (2017)]. DOI: $10.1007 / \mathrm{s} 10812-017-0515-2$

[27] D.S. Filimonenko, V.M. Yasinskii, G.T. Vasilyuk, S.A. Maskevich, A.E. German, V.F. Oskirko, B.S. Lukyanov, V.I. Minkin. In: Proc. Int. Conf. NANOMEETING-2015 (Minsk, 2015), p. 80 .

[28] Г.Т. Василюк, С.А. Маскевич, В.Ф. Аскирка, А.В. Лавыш, С.А. Кургузенков, А.Е. Герман, И.Ф. Свекло, В.М. Ясинский, А.А. Ярошевич, О.И. Кобелева, Т.М. Валова, А.О. Айт, В.А. Барачевский, В.Н. Яровенко, М.М. Краюшкин. Журн. прикл. спектроск., 84 (5), 710 (2017). [J. Appl. Spectrosc., 84 (4), 700 (2017)]. DOI: $10.1007 / \mathrm{s} 10812-017-0543-\mathrm{y}$

[29] V.A. Barachevsky, O.V. Venidiktova, O.I. Kobeleva, A.M. Gorelik, A.O. Ayt, M.M. Krayushkin, A.R. Tameev, G.I. Sigeikin, M.A. Saveliev, G.T. Vasiluyk. IEEENANO 2015: Nanotechnology, Proc. IEEE, 358 (2015).

[30] P.V. Karpach, A.A. Scherbovich, G.T. Vasilyuk, V.I. Stsiapura, A.O. Ayt, V.A. Barachevsky, A.R. Tuktarov, A.A. Khuzin, S.A. Maskevich. J. Fluoresc., 29 (6), 1311 (2019). DOI: $10.1007 / \mathrm{s} 10895-019-02455-4$

[31] A.A. Scherbovich, S.A. Maskevich, P.V. Karpach, G.T. Vasilyuk, V.I. Stsiapura, O.V. Venidiktova, A.O. Ayt, V.A. Barachevsky, A.A. Khuzin, A.R. Tuktarov, M. Artemyev. J. Phys. Chem. C, 124, 27064 (2020).

DOI: $10.1021 /$ acs.jpcc.0c06651

[32] V.A. Barachevsky, O.I. Kobeleva, A.O. Ayt, A.M. Gorelik, T.M. Valova, M.M. Krayushkin, V.N. Yarovenko, K.S. Levchenko, V.V. Kiyko, G.T. Vasilyuk. Opt. Mater., 35, 1805 (2013). DOI: 10.1016/j.optmat.2013.03.005

[33] В.А. Барачевский, О.И. Кобелева, О.В. Венидиктова, А.О. Айт, Г.Т. Василюк, С.А. Маскевич, М.М. Краюшкин. Кристаллография, 64 (4), 820 (2019) [Crystallogr. Rep., 64 (5), 823(2019)]. DOI: 10.1134/S1063774519050055

[34] V.A. Barachevsky, O.V. Venidiktova, T.M. Valova, A.M. Gorelik, R. Vasiliev, A. Khuzin, A.R. Tuktarov, P.V. Karpach, V.I. Stsiapura, G.T. Vasilyuk, S.A. Maskevich. Photochem. Photobiol. Sci., 18, 2661 (2019). DOI: $10.1039 / \mathrm{C} 9 P$ P00341J

[35] P.C. Lee, D. Meisel. J. Phys. Chem., 86, 3391(1982). DOI: $10.1021 / \mathrm{j} 100214 \mathrm{a} 025$

[36] C.N. Lok, C.-M. Ho, R. Chen, Q.-Y. He, W.-Y. Wing-Yiu Yu, H. Sun, P.K.-H. Paul Kwong-Hang Tam, J.-F. Jen-Fu Chiu, C.-M. Chi-Ming Che. J. Biol. Inorg. Chem., 12, 527(2007). DOI: $10.1007 / \mathrm{s} 00775-007-0208-\mathrm{z}$

[37] J. Turkevich. Gold Bull., 18 (3), 8 (1985). DOI:10.1007/BF03216574

[38] J. Kimling, M. Maier, B. Okenve, V. Kotaidis, H. Ballot, A. Plech. JPC B, 110, 15700 (2006). DOI:10.1021/jp061667w 
[39] A. Fedosyuk, A. Radchanka, A. Antanovich, A. Prudnikau, M.A. Kvach, V. Shmanai, M. Artemyev. Langmuir, 32 (8), 1955 (2016). DOI: 10.1021/acs.langmuir.5b04602

[40] А.А. Маскевич, В.И. Степуро, С.А. Кургузенков, А.В. Лавыш. Вест. Гродн. гос. университета, 3 (159), 107 (2013).

[41] D.V. O'Connor, D. Phillips. Time-correlated Single Photon Counting, (Acad. Press, N.Y., 1984).

[42] A.D. Becke. J. Chem. Phys., 98 (3), 5648 (1993). DOI: $10.1063 / 1.464913$

[43] A.D. Becke. Phys. Rev. A, 38 (6), 3098 (1988). DOI: 10.1103/PhysRevA.38.3098

[44] C. Lee, W. Yang, R.G. Parr. Phys. Rev., 37 (2), 785 (1988). DOI: 10.1103/PhysRevB.37.785

[45] О.И. Кобелева, Т.М. Валова, В.А. Барачевский, М.М. Краюшкин, Б.В. Личицкий, А.А. Дудинов, О.Ю. Кузнецова, Г.Е. Адамов, Е.П. Гребенников. Опт. спектр., 109 (1), 106 (2010) [Opt. Spectr., 109 (1), 101 (2010)]. DOI: $10.1134 / S_{0} 030400 \times 10070167$

[46] Г.Т. Василюк. Вестник фонда фундаментальных исследований, (2), 102 (2021).

[47] W.W. Yu, L. Qu, W. Guo, X. Peng. Chem. Mater., 15 (14), 2854 (2003). DOI: 10.1021/cm034081k

[48] А.М. Полуботко, В.П. Челибанов. Опт. спектроск., 120 (1), 99 (2016) [Opt. Spectrosc., 120 (1), 86 (2016)]. DOI: $10.1134 / S_{0} 030400 X 1512019 \mathrm{X}$

[49] И.Р. Набиев, Р.Г. Ефремов. Спектроскопия гигантского комбинационного рассеяния и ее применение к изучению биологических молекул (ВИНИТИ, М.,1989). 